\title{
ATELEL
}

\section{De volta às discussões sobre o significado de paisagem e outras avenças}

\author{
Back to discussions about landscape meaning and other \\ covenants
}

\section{De vuelta a las discusiones sobre el significado de paisaje y otros dilemas asociados}

\author{
Douglas Santos \\ Professor aposentado pela PUC-Sp \\ douglassangeog@yahoo.com.br
}

\begin{abstract}
Resumo
Acompanhando as proposições metafísicas que sobrecarregam o discurso geográfico e, certamente, nossas noções de paisagem, este artigo dialogando com um conjunto de citações disponibilizado pelo professor e amigo Nicolás Ortega Cantero, em uma das aulas ministrada na Universidade Autônoma de Madri, é uma revisita ao tema - lembrando que os artigos que já publiquei sobre o assunto se encontram identificados na bibliografia.
\end{abstract}

Palavras-chave: Geografia, teoria e método, paisagem, território, região.

\begin{abstract}
Following the metaphysical propositions that overload the geographical discourse and, certainly, our conceptions of landscape, this paper is a revisit to the theme and dialogues with a set of quotes, provided by the friend and professor Nicolás Ortega Cantero, in one of his classes given at the Autonomous University of Madrid remember, the articles I have already published about the subject are identified in the bibliography.
\end{abstract}

Keywords: Geography; theory and method; landscape; territory; region

\section{Resumen}

En el marco de las propuestas metafísicas que sobrecargan el discurso geográfico y, por supuesto, nuestras nociones de paisaje, este artículo, dialogando con un conjunto de citas ofrecido por el profesor y amigo Nicolás Ortega Cantero, en una de sus clases en la Universidad Autónoma de Madrid, es una revisita al tema - 
recordando que los artículos que ya he publicado sobre el tema se encuentran identificados en la bibliografía.

Palabras clave: Geografía, teoría y método, paisaje, territorio, región.

\section{Explicações necessárias sobre o contexto que me levou a escrever este artigo}

Aos companheiros de jornada

Nicolás Ortega Cantero e

Antonino Gonzáles

¡Qué pocos se sienten

entusiasmados con lo que

aparece sólo al espíritu! Los

sentidos, el sentimiento, la

pasión ejercen sobre nosotros

un poder mucho mayor, y con

razón, pues hemos nacido, no

para observar y meditar, sino

para vivir.

(Goethe, Teoría de la

naturaleza)

Tudo o que aqui ainda se colocará por escrito é fruto de um amplo conjunto de provocações e silenciamentos. Nesses últimos meses tenho acompanhado dois dos cursos ministrados pelo professor e amigo Nicolás Ortega Cantero na graduação em Geografia da Faculdade de Filosofia da Universidade Autônoma de Madri. Um desses cursos é intitulado de Estudo Geográfico da Paisagem e o outro, Evolução do Pensamento Geográfico.

Os programas desses cursos, distintos no que tange a seus objetivos, em muitos momentos se intercruzam, principalmente quando consideramos que no segundo, focado principalmente nas origens do pensamento geográfico moderno (como diz o próprio programa), tem a figura e a obra de Humboldt como um de seus pilares. Isso faz com que esse curso tenha na categoria paisagem um de seus fundamentos, haja visto a importância que ela possui na obra humboldtiana. Por outro lado, o primeiro curso é estruturado em torno da noção de paisagem, e isso nos devolve aos dilemas propostos por Humboldt e a suas decorrências no que se refere a uma leitura geográfica do mundo.

Vale considerar, ainda com o objetivo de contextualizar o leitor, que participei desses cursos evitando qualquer tipo de intervenção que não tenha sido devidamente 
combinada com Nicolás. Considerei que tais interferências teriam resultados absolutamente perniciosos, enquanto o silêncio nos permite escutar e refletir sobre a riqueza do que está sendo dito. Dessa maneira, tal como nas experiências que vivi entre os anos 2012 e 2013 aqui em Madri, ouvir Nicolás é mergulhar em leituras da Geografia por vezes muito diferentes das minhas, e aproveitar tudo isso para me fazer perguntas, para colocar em dúvida meus pensamentos... uma oportunidade de uma riqueza imensurável.

Por fim, a ideia de escrever o artigo veio de um texto distribuído aos alunos em uma dessas aulas. Nele havia seis observações de diferentes geógrafos sobre o significado de paisagem, proposições que parecem ter sido escolhidas para evidenciar as diferentes leituras que essa categoria traz para os geógrafos e para todos aqueles que sobre ela se debruçam. Quando saímos da sala, comentei com Nicolás que o andamento daquelas discussões havia me colocado a necessidade premente de escrever um artigo. Pois bem... vamos a ele, portanto.

\section{As citações, comentários breves e uma proposição para a teoria do conhecimento}

El paisaje no es, por lo tanto, lo que está ahí, ante nosotros, es un concepto inventado o, mejor dicho, una construcción cultural. El paisaje no es un lugar físico, sino una serie de ideas, sensaciones y sentimientos que elaboramos a partir del lugar. (Maderuelo, 1997, p. 10, grifo do autor)

A proposição de Maderuelo coloca-nos frente a um impasse do ponto de vista epistemológico: se a paisagem não é um lugar físico, mas uma série de ideias, sensações e sentimentos, então a paisagem confunde-se com todo o nosso conhecimento. Vale, sempre, considerar que as ideias que temos sobre as coisas não são as coisas sobre as quais construímos nossas ideias. O problema, nesse caso, se desdobra em duas questões da máxima importância:

$\mathrm{Ou}$ as coisas que temos em nossas mentes só existem ali porque somos capazes de criá-las, isto é, de imaginá-las, e em nada se referem ao mundo material, de modo que nem mesmo podemos saber se de fato nos relacionamos com ele ou, no limite, se ele existe;

Ou as ideias que temos das coisas são o resultado das relações que individual e coletivamente temos com o mundo e, portanto, as coisas existem e é em nossa relação com elas que conseguimos saber o que elas são para nós. O conhecimento, portanto, exige sempre algum nível de materialidade.

Maderuelo parece concordar com a primeira proposição quando fala da paisagem e desemboca na segunda quando nos coloca o lugar como ponto de partida para nossas sensações. Isso nos coloca a possibilidade de afirmarmos que a paisagem só existe em nossas mentes, porém o lugar existe enquanto uma materialidade. Mas... o que 
seria o lugar? Reconhecemos o lugar em nossas mentes e, sendo assim, não seria ele também uma construção cultural? Se o lugar é que nos permite reconhecer a paisagem, não seria a paisagem que nos permitiria reconhecer o lugar e, portanto, não seria ele também uma invenção?

Bom... a citação tal como está posta não nos permite ir muito além dessas perguntas e, portanto, paremos por aqui.

«Un paisaje es una imagen cultural, un modo pictórico de representar, ordenar o simbolizar lo que nos rodea.» (DANIELS; COSGROVE, 1988,p. 1).

A proposição de Daniels e Cosgrove não avança muito nesse embate. É possível inferir que esses autores aproximam a categoria das formulações dadas pela prática das artes plásticas. Fica em questão, portanto: se a paisagem se resume a uma maneira pictórica de ordenar ou simbolizar o que nos rodeia, não seria isso, também, uma maneira do sujeito conhecer o mundo que o rodeia e, portanto, uma ordenação do sensório passível de ser histórica e geograficamente identificável? Não seria possível identificar na diferencialidade das maneiras de se pintar o mundo nas diferentes civilizações e épocas, já, em si mesma, a autorização para inferirmos tal proposição? Por outro lado, considerando que a sobrevivência humana depende da relação que cotidianamente realizamos com todos os demais elementos que nos rodeiam, e que tal relação pressupõe uma simbiose entre a percepção dos sujeitos e as diferentes formas e posições dos objetos, permitindo a cada um de nós inferir a dimensão processual em que estes estão inscritos em relação ao nosso próprio sobreviver, vale ainda considerar que a observação paisagística produz muito mais do que pinturas, pois é nela e com ela que se constitui o próprio sobreviver.

En ecología, el paisaje es considerado directamente como ecosistema -un determinado nivel de análisis ecosistémico cuya amplitud viene definida por la percepción humana- y a él se aplican conceptos como funcionalidad, adaptación, reversibilidad, resiliencia (o elasticidad) comunes en distintos niveles de análisis ecosistémico. (GÓMEZ SAL, 2006,p. 87).

Na proposição de Gómez Sal a tautologia parece ter se superposto à construção de um conceito para paisagem. Assim, se paisagem é o ecossistema, temos como resultante que o ecossistema é a paisagem. O autor percebe a dificuldade e tenta ampliar a abordagem recompondo o conceito em outros termos, de modo que a paisagem deixe 
de ser diretamente o ecossistema e se transforme em um determinado (qual?) nível de análise definido pela percepção humana. Considerando que a proposição mantém-se demasiadamente vaga porque não explicita a que percepção está se referindo, o autor faz uma lista de categorias (que ele chama de conceitos), mas se perde no fato de que nada disso possui clareza e, portanto, o conceito não se explicita.

De toda maneira, o problema se repete, seja porque a paisagem, ao se tornar simples representação, perde seu status de cientificidade, ou seja porque ao se confundir com o fenomênico, ela se torna um emaranhado de proposições vagas (i. é: paisagem $=$ ecossistema), sem que se saiba de fato o que é paisagem.

[...] el paisaje no se reduce a una simple representación, a un simple mecanismo de proyección subjetiva y cultural. [...] el concepto de paisaje no es únicamente una vista, es antes que nada un territorio o un sitio, incluso si este sitio o este territorio son visibles (su ser no se reduce a su visibilidad). (BESSE, 2010, pp. 120-121, grifos do autor).

Besse nos presenteia, de forma mais sofisticada, com o mesmo dilema de Gómez Sal. Se a paisagem não se reduz à simples representação, ela é sobretudo território ou lugar. É possível chamar paisagem de território (não seria melhor afirmar que o território possui uma paisagem)? Se paisagem é o mesmo que território, então, o que é território? Se território é lugar e paisagem é lugar, então o que é lugar? O que é paisagem? Imaginemos e concordemos com a afirmação do autor de que paisagem é mais do que uma projeção subjetiva e cultural; considerando, portanto, que o paisagístico seja uma projeção do sujeito, fica a dúvida sobre o que provoca no sujeito um conjunto de experiências que lhe permite fazer tal projeção, isto é, o que constrói a subjetividade do sujeito e como ela se objetiva. Seria a cultura algo para além, para aquém ou até que prescinda da experiência? Não é a ciência uma das dimensões da cultura? Considerando que há uma segunda citação de Besse, deixemos que o embate se amplie mais adiante.

El paisaje es [...] un lugar y su imagen. Es una realidad física, un nudo de problemas territoriales y es su modo de entendimiento y de reacción - no necesariamente sólo material - con sus habitantes. Es a la vez una figuración y una configuración. (PISÓN, 2009, p. 36 no original).

Interessante notar o posicionamento de Matínez de Pisón ao somar a noção de lugar com a de imagem. Acontece que tal proposição coloca-nos um dilema: a existência do lugar está associada a uma identidade com o fenomênico, mas a imagem é um problema do sujeito que a constrói. Quem percebe o mundo na forma de uma imagem é 
um sujeito, enquanto que o lugar não possui uma imagem, mas sim uma forma. ${ }^{1}$ De toda maneira, a construção conceitual continua sem se resolver. Vejamos: a paisagem é uma realidade física, mas nem sempre a realidade física é uma paisagem (ou é?). Em que escala de observação do sujeito podemos dizer que a imagem percebida e criada - e talvez significada - é uma paisagem? A imagem que percebemos em um microscópio é uma paisagem? E num telescópio? E numa representação pictórica? Um mapa é uma paisagem? Assim, a paisagem aparece aqui como um nó de problemas territoriais, algo como um verdadeiro entroncamento de contradições (parece-me) e, ao mesmo tempo, é a maneira pela qual os sujeitos compreendem e reagem a esse "nó". Transpassando a objetividade do fenomênico em relação à subjetivação e objetivação dos sujeitos que o percebem, a paisagem continua indefinida; é sempre algo sem ser exatamente aquilo e, portanto, vai se tornando uma categoria cientificamente inútil.

La verdadera cuestión es la del estatuto atribuido a lo visible, su función o su significación. En líneas generales: ¿es el espectador el que define el paisaje? En este caso, lo visible es lo relativo a un punto de vista, a un encuadre, es una imagen. O bien, ¿existe lo visible, el paisaje, haya o no mirada? En este caso, lo visible y el paisaje son pensados como objetivos, como una faz exterior, un rostro, una fisonomía, entonces el problema del espectador eventual consiste en ajustarse perceptiva e intelectualmente a esta fisonomía: el paisaje no es una imagen, es una forma. A decir verdad, estas dos posiciones, o hipótesis, constituyen dos polos extremos, entre los cuales hay una tensión en la experiencia paisajística: una tensión entre, por una parte, la actividad del espectador, y, por otra, el hecho de que hay algo que ver, algo que se da a ver. Una posición subjetivista pone el acento en el papel constituyente de la mirada. La realista lo pone en la idea de que hay algo más allá de la representación, algo más que lo simplemente visible. (Besse, 2010, p. 121, grifo do autor).

\footnotetext{
${ }^{1}$ Três livros (ou, pelo menos, os trechos onde o tema é tratado diretamente) devem ser consultados para que o tema tome toda sua amplitude. O primeiro deles é Física, de Aristóteles, onde ele se desdobra na tentativa de explicar o significado de espaço e a noção de lugar acaba por se sobrepor a ele. O segundo é um texto de Bergson voltado a colocar em evidência a relação entre espaço e lugar em Aristóteles. Por fim, o texto de Hegel que, quando procura identificar o significado de natureza, acaba se desdobrando na necessidade de explicitar o significado de lugar (princípio do segundo volume na edição de referência). As referências bibliográficas são as seguintes: ARISTÓTELES. Fisica. Madrid: Editorial Gredos, 1995; BERGSON, H. O que Aristóteles Pensou Sobre o Lugar. Campinas: Editora Unicamp, 2012; HEGEL, G. W. F. Enciclopédia das Ciências Filosóficas em Epítome. Lisboa: Ed. 70, 1988/ 1989 /1992. 3 vols.
} 
A última citação é um retorno a Besse. De uma maneira ou de outra, ela também procura refletir sobre o emaranhado de proposições que estão sendo apontadas nas citações anteriores, inclusive a dele próprio. Ao que parece, portanto, foi colocada ao final como uma espécie de epílogo que poderia responder, pelo menos, a parte das dificuldades já apresentadas. Vamos, portanto, dar um pouco mais de atenção ao texto.

Iniciemos pela preocupação de Besse em colocar o embate na necessidade de se identificar ou construir um "estatuto para o visível", isto é, um conjunto de inferências, pressuposições, conceitos, definições que nos permitam identificar como podemos entender o fato de que, ao nos relacionarmos com o mundo externo a nós, defrontamonos com a condição de poder vê-lo. Afinal, o que será que vemos? Será que são simplesmente os frutos de nossa imaginação? Será que o que vemos é o que existe de fato? Sabemos que outros animais, com outros sistemas óticos, veem o mundo de outra maneira. Imaginamos que o mundo dos pássaros (diferenciadamente a cada espécie) não é visto (e, portanto, entendido?) da mesma maneira que pelos répteis. Qual de nós tem razão? Ou será que nenhum de nós? Nem vale a pena citar a lista de filósofos que consideram que o mundo é "de fato" uma ilusão.

Assim, podemos dizer que a reivindicação de Besse tem sua razão de ser. $\mathrm{O}$ profundo vínculo do discurso geográfico com a noção de Paisagem coloca para a categoria uma responsabilidade ímpar: destruir seu significado como fundamento científico coloca em risco a possibilidade de se destruir toda uma tradição milenar do conhecimento humano.

Sem que possamos pedir permissão a Besse, no entanto, vou propor inicialmente que a dimensão do "ver" seja ampliada para a noção do "sentir". Creio que isso pode mudar qualitativamente nossa discussão sem que o fundamento proposto por Besse seja corrompido. No final das contas, quando colocamos em questão se o que vemos é, de fato, o que vemos, por inferência podemos admitir que todos os nossos sentidos (sejam eles quantos forem) também podem ser colocados em dúvida.

Citando de memória, vale comentar algo que está descrito no livro Espaço e Tempo, dimensões gêmeas: Szamozi (1988) nos conta que certa vez um grupo de neurologistas inverteu (não sei se essa é a expressão correta) o nervo ótico de um sapo, obrigando-o a enxergar invertido, isto é, o que deveria ser percebido como estando acima ou abaixo era visto exatamente ao contrário. Colocado dentro de uma caixa, ao pobre animal foi "servido" um inseto. Ocorre que quando o inseto estava na parte superior, o sapo lançava sua língua para a parte inferior, e assim a inversão do nervo ótico colocou em risco a capacidade de sobrevivência daquele animal. A seguir, o mesmo grupo fez com que um esquiador utilizasse um par de óculos prismático, com o qual também ele passou a ver tudo invertido. Contudo, depois de alguns tombos, paulatinamente o esquiador foi "reprocessando" as informações e, com um pouco de treino, acabou por conseguir controlar seus movimentos, agindo de forma invertida ao que normalmente faria frente às imagens que via. 
Deixemos isso de lado por um momento e vamos a uma segunda citação, agora do texto Lógica Formal, Lógica Dialética de Lefèbvre:

Deixemos seu lugar ao idealismo. Aceitemo-lo inteiramente. Sim, deve-se concordar com Berkeley que é contraditório atribuir existência objetiva a nossas sensações, ao gosto do sal e à cor azul (acrescente-se aqui a paisagem). Sim, é preciso concordar com Kant e com o Sr. Brunschvicg que o mundo 'dado', os fenômenos, são uma poeira múltipla, mutável, contraditória de sensações. Mas, dessa pressuposição, deve-se tirar a conclusão inteiramente inversa. Deve-se inverter o raciocínio idealista porque ele inverte o processo real do conhecimento. Tão logo olho uma estrela, sei que ela não é um pequeno ponto brilhante perdido a algumas centenas de metros no azul sombrio do céu. (...). Meu olho me faz ver como algo quebrado a vara imersa na água; a minha mão, que tateia me prova que ela não é quebrada (...) Um objeto qualquer é o mesmo e, não obstante, jamais é o mesmo: pequeno ou grande, conforme se afaste ou se aproxime, e rico de aspectos diversos. Desde a antiguidade, o ceticismo se fundava nessas contradições, como, por exemplo, na 'ilusão' da vara quebrada; e, a partir disso, criticava nossos sentidos como sendo incapazes de alcançar a verdade. Dessa 'ilusão', a ciência extraiu conclusões inteiramente diversas: a lei da refração. Ela resolveu a contradição entre o olho e o tato." (LEFÈBVRE, 1979, p. 69-70)

Vale, agora, fundirmos o que citei de memória, o texto de Lefebvre e a proposição de Besse: o estatuto do visível. Assim, pergunta Besse: é o espectador o que define a paisagem? Ou ainda, existe o visível, a paisagem, seja ou não observada? Onde está a diferença entre os autores citados e o dilema de Besse? Justamente no fato de que tanto Szamozi quanto Lefebvre, quando se referem ao ver, ao sensório, preocupam-se imediatamente em identificar o que se vê. Seja o inseto, a pista de esqui, a vara ou a estrela, em nenhum deles o visível permanece como algo genérico chamado de paisagem. Nesse contexto proponho, portanto, uma nova pergunta: o que vejo quando vejo a paisagem? É nesse sentido que vai a proposição lefebvriana de inverter o pensamento idealista: se posso dizer que quando vejo árvores, montanhas, prédios, plantações ou qualquer outra coisa, estou vendo paisagens, então posso dizer que: ou estou confundindo o fenomênico com o ato de percebê-lo (e, portanto, com outro fenômeno), ou resolvi identificar todas as coisas que consigo perceber com um único nome, mágico e genérico: Paisagem!

É possível ver (ou perceber) a paisagem? Pensemos em dois caminhos distintos para nos conduzir a alguma resposta:

- se a paisagem fosse uma coisa ou, pelo contrário,

- se coisas dessem a ela a condição de ser algo. 
Ficaremos com a segunda proposição. Sei que vejo as paisagens porque vejo montanhas, florestas, cidades, campos etc. A expressão paisagem, no entanto, não pode substituir a expressão montanhas, tampouco florestas ou quaisquer outras que se queira. O substantivo "montanha" refere-se a um objeto que existe independentemente de minha observação, enquanto que paisagem refere-se ao ato do sujeito de perceber a montanha esta sim, independentemente de como o sujeito a percebe, é que é o percebido. Em outras palavras: não percebemos paisagens, mas assim dizemos porque a expressão está associada a um tipo de percepção e não a algo que é percebido. Colocar em discussão a paisagem nos termos que estamos vendo aqui é apenas a transformação de uma metonímia num substantivo. O que percebemos e chamamos de paisagem são as formas das coisas do mundo nas escalas em que as reconhecemos imediatamente como os nossos ecúmenos.

Acontece que assumir a segunda proposição implica em consequências epistemológicas que só podem ser resolvidas se nos ativermos ao processo pelo qual o sujeito é capaz de conhecer e, assim, nos aproximarmos da identificação do que é que, no final das contas, o sujeito de fato conhece. Isso, no entanto, obriga-nos a encerrar por aqui os comentários em torno de Besse, pois a continuação de seu texto não propõe qualquer conclusão e, por isso mesmo, não procura colocar um ponto final no dilema que ele mesmo propõe (estamos nos referindo ao texto citado... as dificuldades inerentes ao texto completo nos obrigariam a realizar um percurso algo diferente do que estamos fazendo aqui).

Para dar continuidade à construção conceitual a que o tema nos obriga, e com o objetivo de colocar "todas as cartas sobre a mesa", segue uma proposição com a qual tenho trabalhado (com infinitos ajustes) nos últimos 25 anos:

- Paisagem é um movimento na construção do conhecimento e, portanto, não é a identidade de um objeto, mas condição da construção do conhecimento pelo sujeito. Em outras palavras, paisagem não é o fenomênico na sua pura externalidade em relação ao sujeito, mas a forma pela qual a externalidade se torna "coisa para o sujeito" ou "objeto", ou, ainda, e com o sentido de complementar o embate, trata-se de uma "categoria do método" e não uma "categoria do fenomênico".

- Quando tratamos da paisagem, há de se considerar uma evidente relação entre a presença do sujeito e as formas pelas quais ele percebe o mundo. Nesse sentido, a ideia de paisagem é absolutamente imprescindível. Contudo, os tempos dos elementos que dão materialidade à paisagem podem não ser os tempos do sujeito. $\mathrm{O}$ que o sujeito percebe possui muitos tempos diferentes, enquanto o sujeito tem o seu próprio. Assim, ver uma montanha, o movimento de um rio, uma constelação de estrelas ou um automóvel em movimento coloca em questão o tempo do sujeito em relação ao objeto. Pode-se ainda afirmar que a 
observação das formas, por ser também uma observação dos tempos das coisas, nos insere na possibilidade do entendimento dos processos que através delas podem ser identificados e, por fim, a leitura da paisagem é também a possibilidade de um sentido de localização pelo entendimento do significado relacional dos objetos que lhe dá sentido e, portanto, é quando o sujeito se percebe no interior do processo e se movimenta dentro dele. A paisagem é, também e por decorrência, o ponto de partida de um processo de identificação de caminhos, direções, teleologias.

\section{Uma pauta para o entendimento do processo de construção do discurso geográfico}

Temos aqui, portanto, uma "teoria da paisagem" que, para se materializar na sua completude, deve fazer parte de uma teoria da percepção do mundo (em linhas gerais, estamos nos referindo a uma teoria sobre a relação sujeito-objeto ${ }^{2}$ ) e, por decorrência e no limite imposto à percepção de caráter paisagístico, uma parte da teoria geral do conhecimento geográfico, entre outras possibilidades de conhecimento do mundo $^{3}$. Trata-se de uma parte porque a Geografia, enquanto um movimento específico de compreensão das coisas do mundo, não se resume à paisagem. $\mathrm{O}$ conhecimento geográfico está associado a uma grande tradição epistemológica na qual o reconhecimento das coisas do mundo se dá a partir dos questionamentos dos sujeitos quanto ao significado de suas (dos sujeitos) posições relativas no interior qualquer sistema de referência que sejam capazes de criar. Por conseguinte, o onde estar das coisas do mundo em relação ao onde estar de cada um de nós coloca-se como condição da compreensão que podemos ter dos processos que definem nosso viver no mundo e, mais do que isso, o existir do conjunto de processos que, direta ou indiretamente relacionados a nós, definem o existir do que chamamos de mundo. Nesse contexto, a noção da paisagem é somente um dos recursos de que dispomos para a construção de respostas à especificidade de nossa pergunta.

Assim, dá-se como fato que uma teoria da paisagem, resumida em si mesma, é um edifício conceitual sem sustentação. Quando nos atemos à paisagem em si e para si,

\footnotetext{
${ }^{2}$ Para avançar minimamente na proposição, vale consultar o texto de BLOCH, Ernst. Sujeto-objeto - El Pensamiento de Hegel. México: Ed. Fondo de Cultura Económica, 1985, além do clássico entre os clássicos, que é o texto de HEGEL, G. W. F. Fenomenologia do Espírito. 2 vols. Petrópolis: Vozes, 1992, sem perder de vista o texto já citado de LEFEBVRE, 1979.

${ }^{3}$ Evitaremos aqui identificar as descrições literárias ou as manifestações das artes plásticas como discursos geográficos, considerando que os objetivos da arte e os da Geografia são distintos. Nada nos impede, no entanto, de analisar geograficamente a manifestação artística, nem de expressar artisticamente a geograficidade do mundo.
} 
deixamos de lado o seu papel na construção do conhecimento e imaginamos que, identificando seu significado, inferimos um discurso geográfico completo.

Vale, nesse sentido, considerar que edifícios semelhantes e, portanto, incapazes de se manterem em pé, são construídos toda vez que o uso isolado das demais categorias geográficas, tais como espaço, território, região, ecúmeno e assim por diante, são confundidas com o estatuto epistemológico necessário à existência de uma ciência. Aqui também temos o uso abusivo de metonímias, onde a parte é tomada como sendo o todo.

Com o objetivo, portanto, de impedir que a discussão do significado de paisagem - no interior do discurso geográfico - se coloque sem sustentação, há de se considerar que, sendo a Paisagem uma categoria do método, é preciso identificar que, por estar associada ao processo geral de percepção dos sujeitos em relação às formas do mundo, na escala do ecúmeno humano, temos de desdobrar a experiência de tal sujeito à condição necessária de tornar o percebido em percebido pensado, isto é, passar da relação entre formas à relação entre significados. Deve-se considerar, no entanto, que a identificação das formas, do ponto de vista geográfico, só adquire sentido quando tal percepção está a serviço do reconhecimento do papel que a localização de cada um dos elementos percebidos desempenha em nos ajudar a identificar e compreender o processo que lhes dá sentido e significado. A esse movimento de ordenação chamaremos aqui, com base na extensa tradição geográfica, de território. Assim, podemos afirmar que Território também não é uma coisa, mas o processo pelo qual o sujeito transforma a paisagem (percepção) em conhecimento (conceito).

Como proposição geral, tal como fiz com paisagem, o desenrolar necessário dessas proposições nos obriga a afirmar que Território é o segundo movimento na construção do conhecimento geográfico, justamente aquele que permite ao sujeito transformar a percepção das formas em reconhecimento das localizações, isto é, em pensamento ordenado. Território é, por definição, a categoria da ordem e, portanto, não é uma identidade do objeto, mas uma condição da construção do conhecimento pelo sujeito - trata-se do sensório pensado ou o "concreto em pensamento". Assim, território não é algo em si e para si sem que seja, igualmente, a ordem como se realiza a construção do "saber do sujeito". Todo território possui sua paisagem e, portanto, estamos frente à relação entre aparência e essência, entre forma e conteúdo, entre o que percebo e o significado que construo a partir do percebido, entre o imediato e o mediatizado, entre o sentir e a cultura ou, enfim, frente ao processo mesmo de hominização do homem.

Acontece que quando chegamos ao território ainda não chegamos à Geografia. $\mathrm{O}$ discurso científico exige que o sujeito identifique e construa uma simbiose entre suas dúvidas e o fenomênico sobre o qual reflete. Trata-se, portanto, do fato de que todo discurso, isto é, a ordem na forma de conceito, é um recorte do objeto e, portanto, sua reobjetivação. É o objeto para o sujeito, ou o mundo visto a partir da intencionalidade de quem constrói algum tipo de conhecimento e, nesse caso, expondo a localização do percebido enquanto resposta possível do questionamento do sujeito. Quando tentamos 
compreender os processos do mundo, não o fazemos tomando a totalidade do percebido como fundamento - isso nos levaria ao caos. Da mesma maneira, não temos como colocar todo o percebido como uma ordenação porque, a princípio, toda a ordem é ordem no interior de um processo e, se não temos o processo, a ordem se esvazia de significação. Assim, tanto a percepção como a ordenação realizam-se tendo como parâmetro a dúvida do sujeito e, portanto, o objetivo que dá fundamento ao seu "perceber do mundo".

A esse recorte temático, ponto de partida e de chegada do discurso geográfico, chamarei aqui de Região e, tal como nos casos anteriores, sintetizo a proposição nos seguintes termos:

- Região é o terceiro movimento na construção do conhecimento e, portanto, não é uma identidade do objeto, mas uma condição da construção do conhecimento pelo sujeito. É o recorte temático do território que nos permite a construção ou reconhecimento das fronteiras e, portanto, a condição da cartografação. É a prédefinição da percepção do sujeito com a qual ele busca reconhecer as formas do mundo (paisagem) e ordenar o pecebido (território) para responder a seu questionamento: como a disposição topológica dos objetos define a geograficidade dos processos?

Muitos embates já se fizeram em nome de defender ou criticar o significado de região ${ }^{4}$. Creio, no entanto, que a questão não é criar novas categorias, mas ampliar os conceitos que lhes fornecem significado, procurando compreender as demandas colocadas pelo desenvolvimento da pesquisa e da reflexão.

Como sabemos, também na tradição geográfica, Região carrega as mesmas dificuldades conceituais de paisagem e território. Nascida como categoria científica na safra das intuições geniais de La Blache, a categoria atravessa o século XX sem que se possa definir com clareza o que delimita uma região e como fazemos para estudá-la; nisso, também nos coloca frente à constante dúvida quanto aos parâmetros que podem indicar que saímos de uma região e chegamos a outra. Mesmo que saibamos que, do ponto de vista lablacheano, isso seria algo tão simplório como o fato de que ao percebermos mudanças na paisagem saberemos que mudamos de região, na discussão não está colocada uma das dificuldades maiores do processo: em que escala e com que critérios devemos perceber que a mudança do paisagístico é, sempre, uma mudança

\footnotetext{
${ }^{4}$ A título de exemplo, vale citar a proposição de Lacoste (1988), para quem Região é um Conceito Obstáculo, ou a de Moreira, que identifica a categoria aos seus fundamentos agraristas e propõe substituí-la pela noção de rede (MOREIRA, 2007).
} 
regional? Por fim, mesmo que tenhamos feito algum tipo de exercício escalar de caráter aritmético [como fez o próprio Lacoste (1988)], a necessidade de confundir um processo de caracterização (um ato do sujeito) com o fenomênico em seu plano mais geral transformou a noção de região num confuso emaranhado de conceitos cuja aplicabilidade está mais a serviço da estereotipação do que, propriamente, do conhecimento científico. Exemplos clássicos, como a divisão regional do Brasil, a divisão do mundo em continentes e delírios como "epistemologia do sul", mundo subdesenvolvido, África Negra, América Latina e tantos outros, só demonstram que toda divisão regional é um recorte temático que, sem ser explicitado, guarda consigo a ausência do conceito como forma básica de carregar de certeza um discurso que se fundamenta no engano.

Reafirmando que a definição de região, independentemente da explicitação epistemológica do sujeito que a faz, subentende a existência de um recorte temático por parte do observador, vale lembrar, ainda, que a existência de regiões montanhosas ou planas, florestadas ou desérticas, urbanas ou agrárias ou quaisquer outras formas de identificação delimitativa do território só pode ser feita se tematizarmos nosso olhar pois, no final das contas, nada impede que uma cidade seja cercada por uma floresta ou exista sobre uma montanha. É nesse ponto que o percebido e o ordenado se tornam discurso ou, ainda, que paisagem e território se tornam região, isto é, o discurso geográfico propriamente dito.

As demais avenças, portanto, devem denunciar a necessidade de tornar a Geografia algo que se resuma a um estudo da paisagem, ou do território, ou da região e, portanto, que confunda a intenção do sujeito com as categorias que utiliza para construir suas dúvidas e suas respostas ${ }^{5}$. O embate, infelizmente, não termina por aí. Há também os que tentam transformar a Geografia em uma "espaciologia", o que significa que, deixando de lado as categorias do método, se perdem nas categorias do fenomênico, confundindo suas ordens como se essas fossem o que dele imaginam seus sujeitos e a isso se resumisse a possibilidade do conhecimento. Mas isso, sem dúvida, já é assunto para outros e muitos outros artigos.

\section{Referências}

BESSE, J.-M. La fisionomía del paisaje: de Alexander von Humboldt a Paul Vidal de la Blache. In : . La sombra de las cosas. Sobre paisaje y geografia. Trad. Marga Neira. Madrid: Biblioteca Nueva, 2010.

${ }^{5}$ Fiz alguns exercícios em torno do tema no artigo: SANTOS, D. Um Objeto para a Geografia. Sobre as Armadilhas que Construímos e o que Devemos Fazer com Elas. Terra Livre, n. 30, São Paulo: AGB Nacional, 2008.

${ }^{6}$ No Brasil, o autor mais conhecido com esse tipo de proposição é Milton Santos. 
DANIELS, S.; COSGROVE, D. Introduction: iconography and landscape. In: DANIELS, S.; COSGROVE, D. (eds.). The iconography of landscape. Essays on the symbolic representation, design and use of past environments. Cambridge: Cambridge University Press, 1988.

GÓMEZ SAL, A. La naturaleza en el paisaje. In: MADERUELO, Javier (dir.). Paisaje y pensamento. Madrid: Fundación Beulas, CDAN y Abada Editores, 2006.

LACOSTE, Y. A geografia - isso serve, em primeiro lugar, para fazer a guerra. Campinas: Papirus, 1988.

LEFEBVRE, H. Lógica Formal/ Lógica Dialética. Rio de Janeiro: Ed. Civ. Bras., 1979.

MADERUELO, J. Introducción: el Paisaje. In: (dir.). El Paisaje. Huesca: Diputación de Huesca, 1997.

MARTÍNEZ DE PISÓN, E. Miradas sobre el paisaje. Madrid: Biblioteca Nueva, 2009.

MOREIRA, R. Da Região à Rede e ao Lugar: a nova realidade e o novo olhar geográfico sobre o mundo. Revista ETC..., Espaço, Tempo e Crítica. n. 1 (3), v. 1, p. 55-70 1 de junho de 2007.

SANTOS, D. Paisagem, música popular e identidade no Brasil. In Ateliê Geográfico. V 9, n. 1 p. 22-49. 2015 - acesso em 21/07/2016 em https://revistas.ufg.br/atelie/issue/view/1496/showToc

SANTOS, D. Leituras Geográficas sobre a Paisagem, in Olhares Geográficos Sobre Paisagem e Natureza, org. Mara Aline Ribeiro e Edvaldo Cesar Moretti. (pp. 35 a 50) Tupã, ANAP, 2018. Acesso gratuito em https://www.amigosdanatureza.org.br/biblioteca/livros/item/cod/176

SZAMOSI, G. Tempo \& Espaço: As Dimensões Gêmeas. Rio de Janeiro: Jorge Zahar, 1988.

\section{Douglas Santos}

Doutor em Ciências Sociais pela Pontifícia Universidade Católica de São Paulo, mestre em Geografia Humana pela Universidade de São Paulo. Professor aposentado pela PUC-SP, professor colaborador na UFGD, Professor convidado na Universidade Pedagógica de Moçambique.

Calle Canoa, 43 bajo 1. CP 28042, Madrid/ Madrid, España.

E-mail: douglassangeog@gmail.com 